\title{
MEIO AMBIENTE, A URGÊNCIA DA PROTEÇÃO E DA SUSTENTABILIDADE
}

\section{ARTIGO ORIGINAL}

SILVA, Valéria Gonçalves ${ }^{1}$

SILVA, Valéria Gonçalves. Meio Ambiente, a urgência da proteção e da sustentabilidade. Revista Científica Multidisciplinar Núcleo do Conhecimento. Ano 05, Ed. 03, Vol. 04, pp. 05-19. Março de 2020. ISSN: 2448-0959, Link de acesso: https://www.nucleodoconhecimento.com.br/lei/urgencia-da-protecao

\section{RESUMO}

O Brasil possui uma grande variedade de recursos naturais; todavia, desde os tempos coloniais, atividades econômicas estiveram diretamente vinculadas à exploração desses recursos, tanto que, em consequência da ampla exploração e do crescimento populacional, na atualidade, há sérios problemas relacionados ao meio ambiente. Nesse contexto, pode-se verificar que a convergência no tocante a demandas na área ambiental cresceu significativamente no país, e, com ela, a urgência de ações para se minimizarem os efeitos danosos causados ao meio ambiente. Diante desse cenário, a sociedade moderna passou a cobrar maior responsabilidade por parte de empresas e do Estado, exigindo a adoção de um comportamento novo e diferenciado. A pressão sobre empresas foi motivada por diversos fatores, podendo-se destacar: pressão do mercado, exigências previstas em requisitos legais, bem como preservação e melhoria de imagem institucional junto aos consumidores. Dessa forma, empresas foram compelidas à incorporação da variável ambiental na gestão empresarial. Assim, - Sistema de Gestão Ambiental tornou-se uma estratégia de negócio que vem crescendo gradativamente no meio empresarial. O presente artigo tem, pois, o escopo de verificar, na forma de revisão bibliográfica, as principais formas de proteção ao

\footnotetext{
${ }^{1}$ Pós-graduada em Letras: Português e Literatura, Ensino da Língua Portuguesa, e Graduada em Português e Inglês.
} 
meio ambiente brasileiro, em termos de legislação e gestão ambiental relacionada à sustentabilidade, podendo-se constatar, pelo estudo realizado, que o Brasil conta com uma legislação ambiental ampla, considerada uma das mais completas e avançadas do mundo (destacando-se a própria Constituição Federal). Já em relação à sustentabilidade, verifica-se que a gestão ambiental vem-se destacando como uma ferramenta de planejamento e controle, contribuindo efetivamente para com 0 desenvolvimento econômico de forma sustentável.

Palavras-chave: Gestão ambiental, sustentabilidade.

\section{INTRODUÇÃO}

Desde os tempos do Brasil colonial, a inserção brasileira na atividade econômica está intimamente ligada à exploração de recursos naturais, a tal ponto em que os principais produtos que configuravam os ciclos econômicos nas diversas regiões do país relacionavam-se, basicamente, à exploração e à exportação desses recursos.

A exploração dos recursos ambientais iniciou-se no século XVI, com o pau-brasil, e, posteriormente, com a cana-de-açúcar, intensificando-se com o ciclo do ouro, nos séculos XVII e XVIII, e do café, já no século XIX e início do século XX. Em meados do século $X X$, com o desenvolvimento da industrialização no país, as exportações brasileiras foram ampliadas e os produtos minerais, intensivos em energia e poluição, como os metalúrgicos, começaram a ser explorados.

Essas mudanças, embora tenham ocorrido simultaneamente ao processo de modernização das estruturas produtiva e social brasileiras, resultaram em consequências ambientais indesejáveis. Há que destacar que a Revolução Industrial possibilitou à sociedade brasileira vivenciar um desenvolvimento tecnológico intenso, todavia esse desenvolvimento só foi conquistado devido ao acentuado uso de energia fóssil e de intensa exploração dos recursos ambientais.

$\mathrm{Na}$ atualidade, o Brasil, apesar de possuir enorme reserva de recursos naturais, enfrenta grandes problemas, como os relacionados a recursos hídricos, que, embora 
sejam abundantes, não há uma adequada distribuição deles nas regiões brasileiras. A poluição de rios também é outro problema que compromete a qualidade da água, devido à presença de metais pesados derivados de atividades industriais e de coliformes fecais, além de outros poluentes, oriundos de esgoto doméstico.

O crescimento populacional, somado à falta de reciclagem do lixo, vem agravando ainda mais a poluição ambiental e deixando, para as próximas gerações, sérios problemas a serem solucionados. A poluição do ar é outro problema grave e constituise no principal fator de risco ambiental para a saúde humana, a nível mundial. Nos grandes centros urbanos, esse problema é ainda mais intenso, sendo frequentes os dias em que a poluição do ar atinge níveis críticos.

Nesse contexto, pode-se verificar que a convergência no tocante a demandas na área ambiental cresceu significativamente no país, e, com ela, a urgência de ações para se minimizarem os efeitos danosos causados ao meio ambiente. Atualmente, há uma crescente preocupação em se conciliar o desenvolvimento econômico com questões relacionadas ao meio ambiente. Essa preocupação é perceptível tanto na esfera privada quanto na pública.

É incontestável a importância do desenvolvimento econômico na sociedade contemporânea. E esse crescimento econômico, que inclui tecnologias modernas e alta renda per capita, é inconcebível sem um moderno setor manufatureiro (KALDOR, 1978). Nesse contexto, um país que se especialize em produtos primários e tenha que importar produtos industrializados dificilmente será um país com alta renda per capita.

Emerge, assim, o interesse da sociedade moderna em aprofundar o conhecimento sobre a proteção dos recursos naturais, com o intuito de amenizar ou mesmo anular agressões ao meio ambiente e associá-lo ao desenvolvimento econômico. Esse interesse advém principalmente da necessidade de garantir condições à coletividade de usufruir das riquezas do meio ambiente, mas, ao mesmo tempo, assegurar a preservação delas para a sociedade contemporânea e para as futuras gerações. 
A garantia desse direito está prevista no Art. 225 da Constituição brasileira. De acordo com esse artigo, todos os cidadãos têm direito ao meio ambiente ecologicamente equilibrado, bem de uso comum do povo e essencial à sadia qualidade de vida, impondo-se ao poder público e à coletividade o dever de defendê-lo e preservá-lo para presentes e futuras gerações.

Frente ao desafio que a sociedade moderna enfrenta na conciliação do desenvolvimento econômico com a proteção ambiental, é de suma importância ter conhecimento dos principais meios de proteção ao meio ambiente brasileiro, em termos de legislação e gestão ambiental. Nessa conjuntura, o presente artigo tem como objetivo identificar, no ordenamento jurídico brasileiro, os principais meios de proteção ambiental, assim como a relação entre gestão ambiental e sustentabilidade, através de pesquisa bibliográfica.

\section{A IMPORTÂNCIA DA LEGISLAÇÃO AMBIENTAL}

Em termos de legislação ambiental, a brasileira é considerada uma das mais completas e avançadas do mundo. A legislação brasileira foi aprimorada com o objetivo de proteger o meio ambiente de abusos, bem como reduzir as consequências devastadoras da exploração. O aprimoramento da legislação, na atualidade, configura-se em um ponto importante para a proteção ambiental no país.

Diante disso, é importante verificar as normas jurídicas brasileiras, relacionadas à proteção ambiental. O sistema jurídico brasileiro possui um importante ordenamento jurídico, estruturado no Direito Ambiental, com vistas ao controle, à fiscalização e à atuação preventiva ao dano ambiental, agregando, para tanto, diversas frentes de proteção ao meio ambiente.

A Constituição Federal, lei maior do país, foi a primeira a tratar de modo ostensivo a questão ambiental, prevendo mecanismos de proteção e de controle. Por isso, a Constituição de 1988 foi considerada por muitos como a Constituição Verde. De acordo com seu Art. 225, Inciso VII, todos têm direito ao meio ambiente ecologicamente equilibrado, cabendo ao Poder Público, dentre outras medidas, 
proteger a fauna e a flora. Além disso, o artigo veda práticas que coloquem em risco sua função ecológica e provoquem a extinção de espécies ou submetam animais a crueldade.

Em seu Título VIII, Capítulo VI, Art. 225, caput, que trata da Ordem Social, preceituase que "(...) todos têm direito ao meio ambiente ecologicamente equilibrado, bem de uso comum do povo e essencial à sadia qualidade de vida.". Impõe-se, também, ao Poder Público e à coletividade, o dever de defender e preservar o meio ambiente para presentes e futuras gerações.

Através de um regramento moderno e inovador, a Constituição de 1988 também concedeu o direito à propriedade, mas condiciona esse direito a vários princípios, dentre os quais a proteção ao meio ambiente. Devido à importância das questões ambientais, a matéria foi abordada em outros títulos e capítulos, referendando a importância da proteção e da preservação do meio ambiente.

A Lei o 9.605/98 configurou-se, também, em um avanço na proteção ambiental, referindo-se aos crimes ambientais e determinando sanções penais e administrativas, derivadas de condutas e atividades lesivas ao meio ambiente.

Antes da inclusão da Lei 9.605/98 no ordenamento jurídico brasileiro, a política criminal referente ao setor ecológico, mostrava-se quase ineficiente e ultrapassada, enquanto no âmbito civil a legislação ambiental tanto em nível constitucional quanto infraconstitucional era uma das mais avançadas. Pairava a latência de que a ciência criminal acompanhasse a evolução do mundo moderno, incluindo aí a proteção às condições naturais indispensáveis à vida, com ênfase aos seres da biota animal, florestal, e a proteção a não poluição dos bens ambientais. (FREITAS; GARCIA, 2009)

Com a instituição de sanções penais e administrativas derivadas de condutas e atividades lesivas ao meio ambiente, passou-se a adotar uma postura diferenciada em relação ao meio ambiente. $\mathrm{O}$ crime está relacionado à violação do direito:

Crime é uma violação ao direito. Assim, será um crime ambiental todo e qualquer dano ou prejuízo causado aos elementos que compõem o 
ambiente: flora, fauna, recursos naturais e o patrimônio cultural. Por violar direito protegido, todo crime é passível de sanção (penalização), que é regulado por lei. (DURAM, 2019, n.p.)

Antes da lei, os poluidores e os causadores de degradação ambiental não recebiam nenhuma penalidade por suas atitudes contra o meio ambiente. Assim, muitos empresários aproveitavam-se da falta de legislação para degradar o meio ambiente. Exemplo disso eram obras de mineração, as quais causavam extensas degradações ambientais, onde o máximo que a legislação previa era o pagamento de algum valor como forma de indenização aos donos de terras vizinhas. Além disso, era ignorada pelos empresários qualquer tipo de prática de preservação ambiental que pudesse ser aplicada a seus negócios.

É importante destacar que a primordial finalidade da Lei oํ 9.605/98 constitui-se na reparação do dano ambiental. Por essa razão, a maioria dos dispositivos da parte geral está relacionada à questão. A lei tem, pois, o objetivo tanto preventivo quanto repressivo, no sentido de que dispõe de fixação de valor para reparação de dano ambiental através de sentença penal condenatória, enquanto que a prevenção ocorre devido ao temor da pena e da indenização.

Com a Lei ํㅜ 9.605/98, as penas foram uniformizadas e tiveram gradação adequada. As infrações foram claramente definidas, contrariamente ao que ocorria, na legislação anterior, a qual definia a responsabilidade das pessoas jurídicas, mas não das pessoas físicas, ou seja, as grandes empresas eram responsabilizadas pelos danos que os empreendimentos causavam ao meio ambiente.

Incluem-se, nos crimes ambientais, condutas que ignoram normas ambientais, mesmo que não estejam relacionadas diretamente a danos ao meio ambiente, além de agressões que ultrapassam os limites estabelecidos por lei. Enquadram-se, nesses casos, empreendimentos que não possuem a devida licença ambiental, incorrendo em desobediência à exigência da legislação ambiental e, consequentemente, são passíveis de punição por multa e/ou detenção. 
A Lei de Crimes Ambientais prevê que as penas sejam aplicadas conforme a gravidade da infração. Quanto mais reprovável for a conduta, mais severa será a punição do ato lesivo. A pena pode ser privativa de liberdade, quando o sujeito é condenado a cumprir sua pena em regime penitenciário, ou restritiva de direitos, onde se enquadram as penalidades: prestação de serviço à comunidade, interdição temporária de direitos, suspensão de atividades, prestação pecuniária, recolhimento domiciliar ou multa.

A legislação prevê penalizações diferenciadas para pessoa jurídica (empresa) que viole algum direito ambiental, podendo ser penalizada com multa e/ou restrição de direitos, suspensão parcial ou total das atividades, interdição temporária do estabelecimento, obra ou atividade, proibição de contratar com o Poder Público, bem como dele obter subsídios, subvenções ou doações.

O crime ambiental também é passível de ação civil pública, a qual foi regulamentada pela Lei $n^{0} 7.347 / 85$. A ação civil é um instrumento jurídico de proteção ao meio ambiente que tem como objetivo a reparação do dano onde ocorreu a lesão de recursos ambientais. A ação civil poderá ser proposta pelo Ministério Público, Defensoria Pública, União, Estados, Distrito Federal, Municípios, empresas públicas, fundações, sociedades de economia mista e associações com finalidade de proteção ao meio ambiente.

Outro avanço foi a instituição da Lei № 6.938, publicada em 31 de agosto de 1981, que institui a Política Nacional de Meio Ambiente (PNMA), um marco e importante avanço em proteção ao meio ambiente brasileiro. Com a nova legislação, os recursos naturais, que antes eram explorados sem nenhuma supervisão, passaram a ser monitorados, possibilitando, assim, um melhor acompanhamento pelos órgãos fiscalizadores, o que favoreceu o incremento da preservação ambiental.

O licenciamento ambiental também se configura em outro avanço e tem sido uma ferramenta importante, pois regulamenta ações de empresários. O licenciamento ambiental é o instrumento que certifica que o empresário está cumprindo a legislação e, para obter o certificado, independente do porte de sua organização, precisa 
conhecer as necessidades e as restrições ambientais do local e adequar-se à legislação ambiental competente.

Com o licenciamento ambiental, almeja-se que o empresário conheça e ponha em prática as medidas preventivas e de controle que são necessárias e compatíveis com o desenvolvimento sustentável, sendo de suma importância o papel do empreendedor, que deve identificar os efeitos que seu negócio possa causar ao meio ambiente, bem como a forma de gerenciá-lo.

O empreendedor deve ter consciência de que, para explorar os recursos naturais de uma região, precisa ter conhecimento das necessidades da comunidade e das restrições de exploração local, sendo necessário cumprir todas as exigências legais para obter a licença ambiental. O objetivo disso é garantir que medidas preventivas e de controle possam ser adotadas em seus empreendimentos.

A adequação das organizações à legislação ambiental configura-se em uma premissa para se alcançar um desenvolvimento econômico e social, sem, contudo, comprometer a proteção ambiental. É preciso proteger o meio ambiente de ações exploratórias, sem o devido controle e respeito a normas ambientais.

\section{GESTÃO AMBIENTAL E SUA CONTRIBUIÇÃO PARA A SUSTENTABILIDADE}

Há, na área ambiental, vários questionamentos e muitos desafios, o que tornou a questão ambiental um dos mais importantes desafios da sociedade contemporânea. Não há necessidade de estudos aprofundados para se concluir que a preservação do meio ambiente é essencial e constitui-se na única forma de garantir a sobrevivência das gerações futuras.

Por outro lado, a questão ambiental está diretamente relacionada à atividade econômica. A ideia do Direito Ambiental brasileiro é que ele está intimamente ligado ao desenvolvimento econômico e ao desenvolvimento social, e não apenas em matéria de preservação ambiental, propriamente dita (DURAM, 2019). 
A questão primordial da atualidade está em torno da promoção do desenvolvimento econômico e social, mas sem, contudo, comprometer questões ambientais. É nesse contexto que a gestão ambiental vem-se destacando, auxiliando organizações a adequarem-se diante das exigências legais, contribuindo diretamente para com o desenvolvimento sustentável.

É importante entender, nesse contexto, o significado de desenvolvimento sustentável. A origem do termo sustentabilidade é latina, vem de sustentare, que significa sustentar, conservar, proteger e manter em equilíbrio. De acordo com Kato (2008), há um consenso entre os pesquisadores em relação a seu conceito, que deve ser tratado de forma abrangente, pois é uma questão complexa com diversas abordagens.

Meadows; Meadows e Randers (1992) definem a sustentabilidade como uma técnica de desenvolvimento que resulta na melhoria da qualidade de vida e simultaneamente na minimização de impactos ambientais negativos. Diante da realidade social e econômica brasileira, a sustentabilidade representa um caminho a ser seguido ante os desafios que se impõem, sendo, na atualidade, a forma mais efetiva de garantir uma qualidade de vida às presentes e futuras gerações, possibilitando, também, o desenvolvimento da economia e da sociedade.

De acordo com Rodrigo C. Rocha Loures (2009), torna-se evidente que o conceito de sustentabilidade está atrelado à questão ambiental, mas não se reduz a ela. $\mathrm{A}$ sustentabilidade é uma temática vinculada à cultura, à sociedade e ao próprio ser humano. Está associada ao compromisso social e ao processo participativo de construção no qual instituições políticas, sociedade civil e grupos de interesse organizados encontram espaço para exercerem papel de representação política e institucional.

Nesse contexto, verifica-se a importância de os gestores dispensarem atenção a técnicas sustentáveis frente aos problemas ambientais. O emprego dessas técnicas nos processos de produção é essencial para a preservação do meio ambiente e implica, de forma direta, na qualidade de vida das pessoas. Por isso, o emprego de 
técnicas sustentáveis é essencial. Além do mais, muitas vezes, contribuem para com a redução de custos na produção.

É importante destacar que a gestão ambiental surgiu devido à necessidade de um desenvolvimento sustentável. O conceito de gestão ambiental surgiu através da premissa do desenvolvimento sustentável como uma forma de administrar os recursos naturais e as atividades dentro de processos de produção de bens e de serviços. As políticas de gestão ambiental foram, portanto, instituídas pela necessidade de se elaborarem metas e objetivos para se alcançar a sustentabilidade, além de criar um compromisso estatal e empresarial (AQUINO AND GUTIERREZ, 2012):

Neste contexto, a gestão ambiental tem ganhado destaque e uma dimensão estratégia das empresas, como forma de planejar o desenvolvimento, a implantação e manutenção de uma política ambiental para o desenvolvimento sustentável se caracterizam como conjunto de princípios, estratégias e diretrizes de ações e procedimentos para proteger a integridade dos meios físicos e bióticos, bem como dos grupos sociais que deles dependem. Inclui também, o monitoramento e o controle de elementos essenciais à qualidade de vida, em geral, e à salubridade humana, em especial. (PAGÉS, 2015, n.p.)

Assim, a gestão ambiental configura-se na forma de planejar o desenvolvimento, a implantação e a manutenção de uma política ambiental para as organizações públicas e privadas, visando ao desenvolvimento sustentável. Inclui, também, ao processo, o monitoramento e o controle de elementos essenciais à qualidade de vida e à salubridade humana. A gestão ambiental é de extrema importância e utiliza-se de mecanismos e instrumentos de gestão que estabelecem ações precisas:

A gestão ambiental é realizada através de mecanismos e instrumentos de gestão que estabelecem ações precisas e específicas para todos os agentes que participam dos processos produtivos e econômicos. Os problemas identificados são objetivos e as intervenções direcionadas para resultados previamente determinados que busquem a permanente 
melhoria da qualidade dos serviços, produtos e ambientes impactados pelas organizações privadas ou públicas. Este processo de aprimoramento é constante e deve ser estabelecido através de políticas, diretrizes e programas relacionados ao meio ambiente e externo às atividades desenvolvidas, colaborando com outros setores econômicos, comunidades próximas ou afetadas, órgãos ambientais e de saúde pública e do trabalho, desenvolvendo e adotando processos que evitem ou minimizem os impactos ambientais e sociais dos empreendimentos (HENDGES, 2010, n.p.).

Como bem pontuado por Hendges, o êxito da gestão ambiental depende da colaboração de todos os envolvidos, devendo ser incluídas, também, as comunidades próximas ou afetadas, bem como órgãos ambientais e de saúde pública e do trabalho. É essencial que todo trabalho adote processos que evitem ou minimizem impactos ambientais e sociais de empreendimentos. O propósito é usar todo conhecimento, experiência e tecnologia para minimizar os impactos diretos de ações devastadoras sobre o meio ambiente e contribuir diretamente para com a sustentabilidade.

No contexto atual, é fundamental a implantação de um sistema de gestão ambiental. Organizações têm sido pressionadas por diversos fatores, como a pressão do mercado, requisitos legais, preservação e melhoria de imagem institucional. Empresas que já aderiram à Gestão Ambiental e introduziram técnicas de sustentabilidade têm obtido resultados positivos, passando a contar com maior credibilidade junto a seus consumidores, sendo beneficiadas, também, em alguns casos, com redução de custo nos processos de produção e, por conseguinte, maior lucro.

Diante desse cenário, é necessário que o desenvolvimento econômico esteja atrelado à consciência ambiental. As duas questões estão intrinsecamente interligadas, não sendo possível promover o desenvolvimento econômico sem o meio ambiente. Devido à urgência em prover a proteção e a sustentabilidade, a Gestão Ambiental tornou-se, pois, uma estratégia de negócio que vem crescendo gradativamente no meio empresarial. 


\section{CONSIDERAÇÕES FINAIS}

Face ao acima exposto, pode-se verificar que o Brasil, desde os tempos coloniais, teve sua atividade econômica diretamente vinculada à exploração de recursos naturais e atividades poluidoras, o que ocasionou, na atualidade, a convergência no tocante a demandas na área ambiental, e, com ela, a urgência de ações para se minimizarem os efeitos danosos causados ao meio ambiente.

A pressão do mercado contribuiu efetivamente para que empresas elevassem seus investimentos em processos e profissionais especializados, voltados à proteção ambiental e à sustentabilidade, o que proporcionou o surgimento da Gestão Ambiental.

Ainda que seja um processo gradativo, as organizações estão se adequando às novas exigências. As que já iniciaram o processo de Gestão Ambiental direcionado à sustentabilidade têm obtido resultados satisfatórios em seus investimentos. Dentre os resultados positivos, pode-se observar que essas empresas passaram a contar com maior credibilidade junto a seus consumidores, sendo beneficiadas, também, pela redução de custo nos processos de produção, resultando em maior lucro.

É importante destacar que, quanto maior for o número de empresas comprometidas com a sustentabilidade, menor será o volume de danos ambientais. Essa consciência deve ser crescente e incentivada, tanto pelo Poder Público quanto pelos próprios consumidores. É necessário estimular, cada vez mais, inovações tecnológicas éticas e sustentáveis, bem como o comprometimento e o engajamento de cada indivíduo, assim como de organizações públicas e privadas. É preciso que a consciência de cada indivíduo se una e forme uma consciência coletiva de sustentabilidade.

Em relação à legislação ambiental, conforme exposto no trabalho, a brasileira é considerada uma das mais completas e avançadas do mundo. Pode-se verificar que tanto a legislação constitucional quanto a infraconstitucional foi aprimorada com a finalidade de prever mecanismos de proteção e de controle. $\mathrm{O}$ arcabouço jurídico 
brasileiro trata a questão ambiental de modo ostensivo, iniciando-se pela Constituição Federal, que foi intitulada de Constituição Verde.

Há que se destacar, também, a instituição da Lei oํ 9.605/98, que se refere aos crimes ambientais, determinando sanções penais e administrativas, derivadas de condutas e atividades lesivas ao meio ambiente, introduzindo uma postura diferenciada em relação ao meio ambiente. O licenciamento ambiental também se constitui em uma ferramenta importante de proteção ambiental, regulamentando ações empresariais e certificando-se de que as empresas cumprem a legislação.

Por fim, percebe-se, neste artigo, que a legislação ambiental no Brasil é ampla e dispõe de vários mecanismos de proteção, sendo oportuno afirmar que, para que a legislação seja devidamente respeitada e cumprida por todos, é necessário, também, que os órgãos competentes procedam à devida fiscalização das empresas.

\section{REFERÊNCIAS}

AQUINO, M. H. G. and GUTIERREZ, R. H., 2012. Aspectos relevantes das normas de gestão ambiental e responsabilidade social para a tomada de decisão. In VIII Congresso Nacional de Excelência em Gestão, 2012. Rio de Janeiro.

BRASIL. Constituição (1988). Constituição da República Federativa do Brasil. Brasília, 5 de outubro de 1988. Disponível em: <http://www.planalto.gov.br/ccivil_03/constituicao/constituicao.htm>. Acesso em: 15 out. 2019.

. Lei Federal no 6.938, de 31 de agosto de 1981. Dispõe sobre a Política Nacional do Meio Ambiente, seus fins e mecanismos de formulação e aplicação. Disponível em: <http://www.planalto.gov.br/ccivil_03/leis/l6938.htm>. Acesso em: 15 out. 2019.

. Lei Federal no 7.347, de 24 de julho de 1985. Disciplina a ação civil pública de responsabilidade por danos causados ao meio ambiente, ao consumidor, a bens e direitos de valor artístico, estético, histórico, turístico e paisagístico (VETADO) e dá 
outras

providências.

Disponível

em:

$<$ http://www.planalto.gov.br/ccivil_03/leis/L7347orig.htm>. Acesso em: 15 out. 2019. . Lei Federal $n^{0}$ 9.605, de 12 de fevereiro de 1998. Dispõe sobre as sanções penais e administrativas derivadas de condutas e atividades lesivas ao meio ambiente. Disponível em: <http://www.planalto.gov.br/ccivil_03/leis/l9605.htm>. Acesso em: 15 out. 2019.

DURAM, Bárbara Sanches de Souza. A Defesa do Meio Ambiente por Meio do Direito Penal. Disponível em <https://ambitojuridico.com.br/cadernos/direito-ambiental/adefesa-do-meio-ambiente-por-meio-do-direito-penal/>. Acesso em: 12 fev. 2020.

FREITAS, Genivaldo Pereira de; GARCIA, Reinilson Mercado. Os grupos de crimes ambientais previstos na Lei 9.605/98, sujeitos do delito e suas sanções penais. Revista Jus Societas. Ji-Paraná - RO - CEULJI/ULBRA, v. 3, n. 2.

HENDGES, Antonio Sílvio. Ecologia e Gestão Ambiental. Disponível em $<$ https://www.ecodebate.com.br/2010/11/03/ecologia-e-gestao-ambiental-artigo-deantonio-silvio-hendges/>. Acesso em: 12 fev. 2020.

KALDOR, N. Further Essays on Applied Economics. London: Duckworth, 1978.

KATO, C. A. Arquitetura e sustentabilidade: projetar com ciência da energia. Dissertação (Mestrado em Arquitetura e Urbanismo) - Universidade Presbiteriana Mackenzie, São Paulo, 2008.

LOURES, Rodrigo C. Rocha. Sustentabilidade XXI: Educar e inovar sob uma nova consciência. São Paulo: Editora Gente, 2009.

MEADOWS, D. H.; MEADOWS, D. L.; RANDERS, L. Beyond the limits: confronting global collapse, envisioning a sustainable future. Vermont: Chelsea Green Publishing, 1992. 
PAGÉS, GILSON MARCOS. A importância do Gestor Ambiental nos dias atuais. Disponível em: <https://www.dm.jor.br/opiniao/2015/07/a-importancia-do-gestorambiental-nos-dias-atuais/>. Acesso em: 10 fev. 2020.

Enviado: Fevereiro, 2020.

Aprovado: Março, 2020. 